\title{
Comparison of Accuracy of UAV Aerials and Ground Measurements in the Curonian Spit Dunes
}

\author{
Algimantas ČESNULEVIČIUS, Artūras BAUTRĖNAS, \\ Linas BEVAINIS, Neringa MAČIULEVIČIŪTĖ-TURLIENĖ \\ Institute of geosciences, faculty of Chemistry and Geosciences, Vilnius University, \\ M.K.Čiurlionio str.21, Vilnius, LT - 03101, Lithuania \\ algimantas.cesnulevicius@gf.vu.lt; arturas.bautrenas@gf.vu.lt; \\ linas.bevainis@gf.vu.lt; neringa.maciuleviciutelgf.vu.lt
}

\begin{abstract}
Various detailed means are taken to stabilize the dune surface. One of them is the creation of sand traps, which reduce the amount of sand transmissions. Therefore, it is desirable to develop a methodology that will help evaluate the effectiveness of sand traps. The topographic measurements of dune harm the sand surface and cannot be often - twice a year, when 2-3 months would be a better interval. For detailed monitoring an aerial photogrammetry and automated granulometry method is developing for less invasive measurements.

For dune surface analysis were applied topographic mapping and UAV aerial images. These commonly used methods allowed of evaluation the accuracy of photogrammetric methods for the analysis of aeolian processes in dunes and will allow for precise evaluation of changes by doing minimal harm to the surface of the dunes.
\end{abstract}

\section{Introduction}

Detailed measurements of the dunes are carried out for many years to assess the impact of various meteorological and natural phenomena on unstable terrain surfaces. At the end of the twentieth century, large numbers of dunes visitors have exacerbated this problem. Various methods are taken to stabilize the surface in the Curonian Spit. One of them is the creation of barriers (sand traps) to reduce the amount of transmissions. Therefore, it is desirable to develop a methodology that will help evaluate the effectiveness of sand traps for surface stabilisation.

Every time when dune surface is measured, harm is done to the sand surface. If traditional methods are applied, measurements cannot be often - twice a year, when 2-3 months would be a better interval. For detailed monitoring and evaluation of impact of protection measures, an aerial photogrammetry and automated granulometry method is developing for less invasive measurements. This method will allow for precise evaluation of changes by doing minimal harm to the surface of the dune.

An important task is to select the most appropriate methodology for accurate estimation of surface changes. Three methods were parallelly applied for precise evaluation of the dune surface changing: topographic mapping, aerial photogrammetry 
and granulometric sand research. Topographical research and aerial photogrammetry are the most commonly used methods that allowed evaluate the accuracy of photogrammetric methods for the analysis and modelling of aeolian processes in dunes. The novelty of the proposed method is to combine them with microscopic photography of surface sand fractions. We believe that this method will allow for precise evaluation of changes by doing minimal harm to the surface of the dune.

The use of unmanned aerial vehicles allows for fast and inexpensive ways to explore the ground surface and to identify objects of interest (Turner et al., 2012, Whitehead et al., $2014 \mathrm{a}, 2014$ b). On the other hand, the research on assessing precision of aero-images of unmanned aerial vehicles has been scarce (Shahbazi et al., 2015). The accuracy of aero-images received with the help of unmanned aerial vehicles (UAV) can be affected by a big number of factors such as flight altitude, photo camera image quality, UAV route designing, methods of georeferencing and others. An appropriate design of UAV route ensures cruise attitude and constant aero-image coverage of the whole territory. An appropriate flight project and a high-quality photo camera result in efficiency in photogrammetric processing of images. The tested and broadly applied mathematical and photogrammetric algorithms of image processing simplify further investigations. The problems occur designing a 3D model of the territory captured in aero-images. The initial 3D model is created in the conditional coordinate system, which is later linked to the officially used coordinate system. Two variants are employed to connect the coordinates: direct graphical connection of the object position in the aeroimage to the coordinate system (less precise) or linking GPS measurements of fixed objects and coordinates of aero-images. The accuracy of vertical positioning of given points is a highly important factor designing 3D relief models that are used for identification, analysis and mapping of surface changes.

The recent research studies (Benassi et al., 2017; Forlani et al., 2018; Hugenholtz et al., 2013, 2016; Shahbazi et al., 2015; Turner et al., 2012, Ruzgienè et al., 2015; Sužiedelytė-Visockienè et al., 2016) have shown that aiming at high accuracy of vertical positioning of objects, it is not enough to use Global Navigation Satellite System (GNSS) only and Ground Control Points (GCP) has to be applied as well. Such a combined technique allows designing a more accurate digital relief model (DRM), where precision of vertical positioning of points equals $0.7 \mathrm{~cm}$.

Applying UAV photo-images for dune research is complicated by two factors: herbaceous vegetation and temporary snow cover. The height of dunes grass significantly varies during the different year seasons. At summer end the height of the grass stems reaches $15-30 \mathrm{~cm}$ (bushgrass, Calamagrostis epigejos); 40 - $60 \mathrm{~cm}$ (lyme grass, Leymus arenarius) and $50-100 \mathrm{~cm}$ (marram grass, Ammophila arenaria) compared to early spring.

The methods of narrow-spectral and surface thermal analysis are applied for the analysis of structural diversity of vegetation cover on the basis of UAV aero-images (Laliberte, Rango, 2009; Berni et al., 2009, Baluja et al., 2012, Bellvert et al., 2013, Chisholm eta al., 2013, Huesca et al., 2013, Knoth et al., 2013, Lebourgeois et al., 2008; Malthus and Madeira, 1993; Zarco-Tejada et al., 2001; Adams et al., 1999; Zhang et al., 2001).

The research studies mainly focus on the influence of big ligneous plants on mapping of surface elements, whereas the impact of low herbaceous vegetation on low forms of relief has not been exhaustively researched so far (Kaneko and Nohara, 2014; Salami et al., 2014). 
During the winter, the temporary snow cover significantly changes the morphometric parameters of the surface. It is thin on the windward slopes of the dunes, and sometimes it was blown-out away. Meanwhile, the thick layers of snow (0.8 - $1.2 \mathrm{~m})$ are covered in the windward slopes, hollows and depression. This situation complicates the comparison of UAV photo-images taken during the summer and winter.

\section{Research object and methods}

The researches were carried out in two areas of main dune-ridges of the Curonian Spit: Nagliai cognitive path and Parnidis dune (Fig. 1). There is a fee for visiting the Nagliai cognitive path, which slightly limits the number of visitors. The dune of Parnidis is close to the Nida settlement, there is a road to it and its visit is not limited. The research was conducted in different seasons of 2017, 2018 and 2019 years.

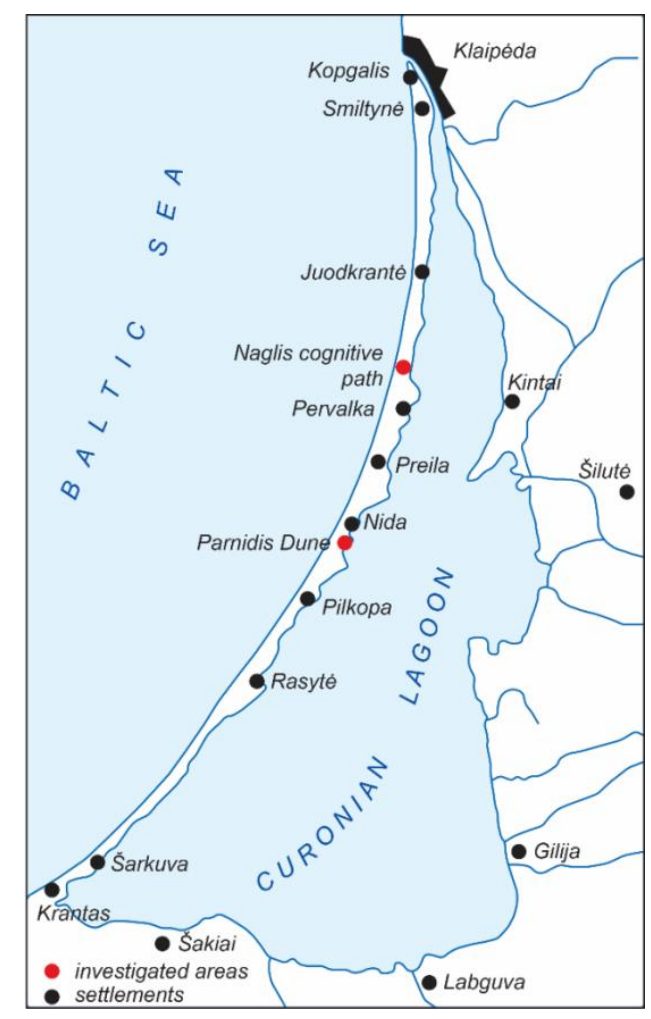

Fig. 1. Investigated area in Curonian Spit.

Surface geodetic measurements and UAV aerial images were used to assess mesorank surface changes. Changes of micro-rank surface changes and microstructure were evaluated using an automated method of recording sand granulometry. The accuracy of 
the meso-rank surface changes was assessed by comparing the maps, which created based on ground-based geodetic measurements and the UAV aerial images.

The surface was mapped by isoline methods in maps. The interpolation between fixed points was based on the Delaunay triangulation principle (Fang and Piegl, 1992). In department of Cartography and Geoinformatics Vilnius University was created software (author Dr. Artūras Bautrenas) for calculating isolines point position. The program is conventionally referred to as "Circle_3p" (Fig. 2).

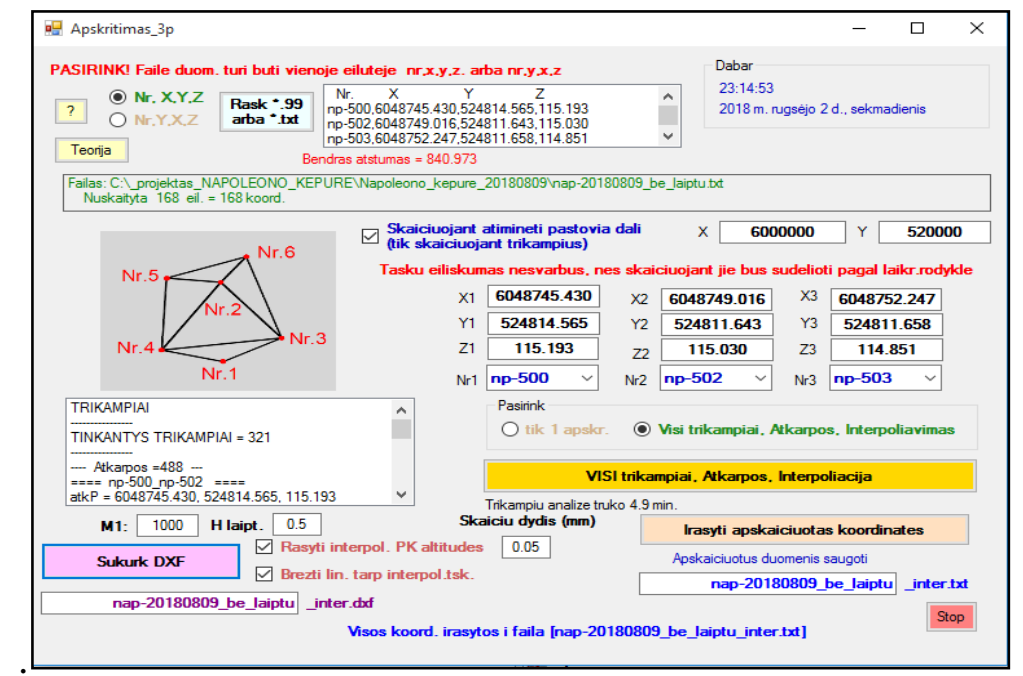

Fig. 2. The application (task) of the management window of the software program "Circle_3p".

The Delaunay triangulation is a connection of dots on a dot plane to make up triangles, so that there are no single points left within the circle. For example, there are four points, among which only the triangles must be selected, so that vertices of those triangles can be used to draw circles, which will correspond to the principles of Delaunay triangulation.

Among these points (theoretically), 4 triangles can be drawn: 1-4-3, 4-2-1, 1-2-3 and 1-4-2. It needs to be checked which of them comply with the Delaunay principles and which do not meet them.

It is obvious that the triangles 1-4-3 and 4-2-3 are not suitable because they fall into the drawn circles: in the first case, point 2, and the second case - point 1 . Therefore, the only correct option for interpolation, its interconnection between triangles 1-2-3 and 1-42, because no outsider points end up in the defined circles (Fig. 3).

Selection of point pairs. Obviously, application of the Delaunay triangulation for the selected 179 measurement points is a complex geometric and mathematical problem that would be very difficult to perform "manually" and computer software is required to perform this task. There are many available programs, which perform division of the point pairs into triangles. However, aiming at the accuracy of the conducted interpolations and their comparison on the basis of this particular topographic photograph, they are not very appropriate because of the unknown algorithm they apply. 


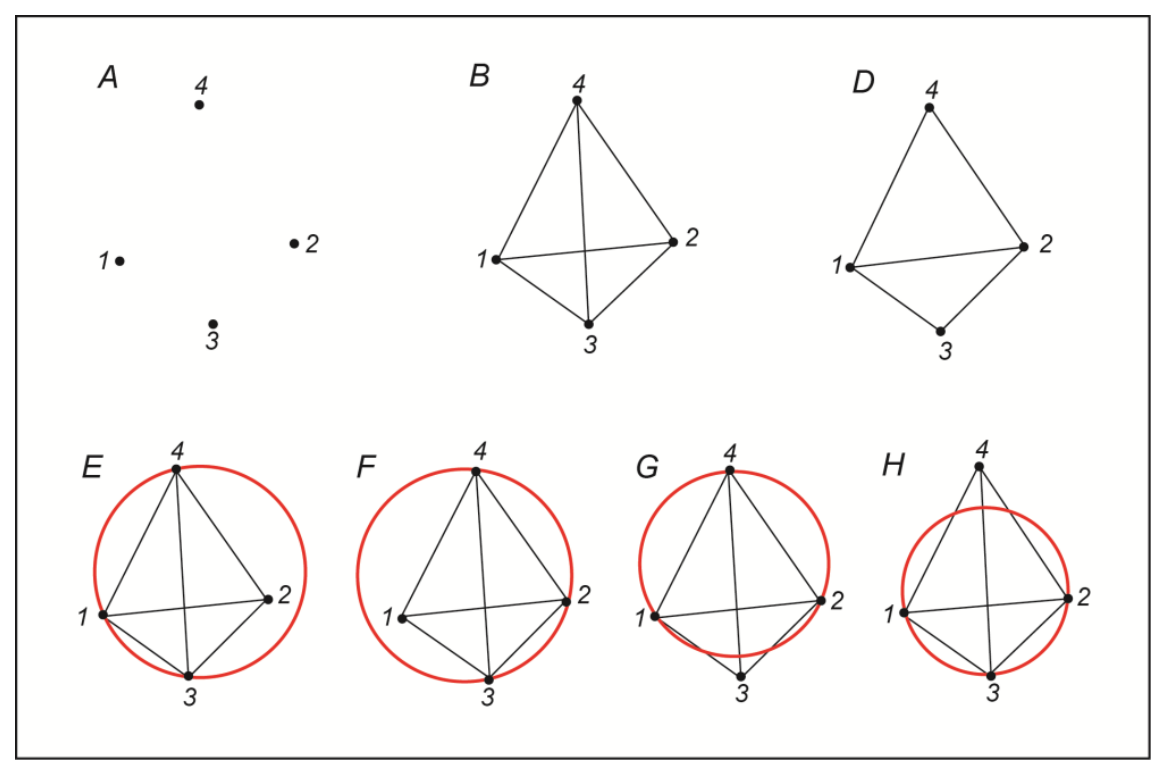

Fig. 3. The points between which interpolation should be performed and the possible arrangements to combine points of triangles.

Principle of program operation. After selecting a set of points (in these topographic photographs 179 points were selected), the program starts checking all the possible points to combine triangles. The coordinates of the centre of the circle are calculated when the vertices of a chosen triangle are drawn through the centre of the circle (Fig. 4), following the formulas 1-3.

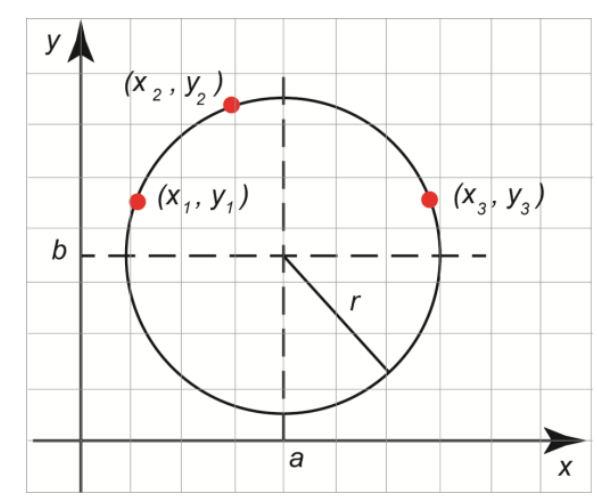

Fig. 4. The calculation of the circle drawn through the centre of the three point coordinates and its radius. Here $\mathrm{x} 1, \mathrm{y} 1, \mathrm{x} 2, \mathrm{y} 2, \mathrm{x} 3, \mathrm{y} 3$ are point coordinates, $\mathrm{x}, \mathrm{y}$ are coordinates of calculated centre of the circle and $r$ is radius of the circle. 


$$
\begin{aligned}
& x=\frac{\left(x_{1}^{2}+y_{1}^{2}\right)\left(y_{2}-y_{3}\right)+\left(x_{2}^{2}+y_{2}^{2}\right)\left(y_{3}-y_{1}\right)+\left(x_{3}^{2}+y_{3}^{2}\right)\left(y_{1}-y_{2}\right)}{2\left(x_{1}\left(y_{2}-y_{3}\right)-y_{1}\left(x_{2}-x_{3}\right)+x_{2} y_{3}-x_{3} y_{2}\right)} \\
& y=\frac{\left(x_{1}^{2}+y_{1}^{2}\right)\left(x_{3}-x_{2}\right)+\left(x_{2}^{2}+y_{2}^{2}\right)\left(x_{1}-x_{3}\right)+\left(x_{3}^{2}+y_{3}^{2}\right)\left(x_{2}-x_{1}\right)}{2\left(x_{1}\left(y_{2}-y_{3}\right)-y_{1}\left(x_{2}-x_{3}\right)+x_{2} y_{3}-x_{3} y_{2}\right)} \\
& r=\sqrt{\left(x-x_{1}\right)^{2}+\left(y-y_{1}\right)^{2}}
\end{aligned}
$$

After the calculation of the coordinates of circle centre, the main condition of the Delaunay triangulation is checked, i.e. if any outsider falls into the defined circle. If this condition is not met, then another triangular connection option is checked. This condition is continuously verified until all the appropriate triangles are selected, and only then interpolation is done between the heights of these triangles with a selected horizontal step (e.g. $0.5 \mathrm{~m}$ ) (see: Fig. 5).

For example:

The points $X_{1}$ and $X_{2}$ are 24 and $24.5 \mathrm{~m}$ respectively (if horizontal step is $0.5 \mathrm{~m}$ ), because these numbers are between $\mathrm{HA}=23.72$ and $\mathrm{HB}=24.64$ (formulas 4-7).

$$
\begin{aligned}
& X_{1}=\frac{\left(H_{X_{1}}-H_{A}\right)}{\left(H_{B}-H_{A}\right)} \times L \\
& X_{2}=\frac{\left(H_{X_{2}}-H_{A}\right)}{\left(H_{B}-H_{A}\right)} \times L \\
& X_{1}=\frac{(24.00-23.72)}{(24.64-23.72)} \times 200.64=61.06 \\
& X_{2}=\frac{(24.50-23.72)}{(24.64-23.72)} \times 200.64=170.11
\end{aligned}
$$

Knowing the distances between horizontals, the coordinates of these points are calculated and these points are plotted accordingly.

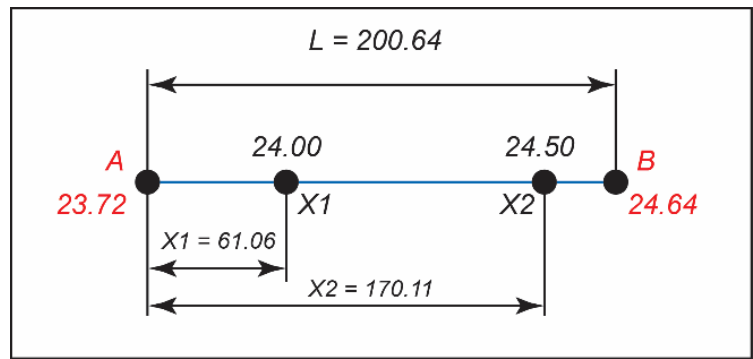

Fig. 5. The calculation of distances to isolines. 
Drawing of a topographic plan. Firstly, the Delaunay triangulation (Fig. 6.) was completed among selected topographic points using the program "Circle_3p". This allowed triangles to be selected, among which interpolation of the triangle vertices was performed.
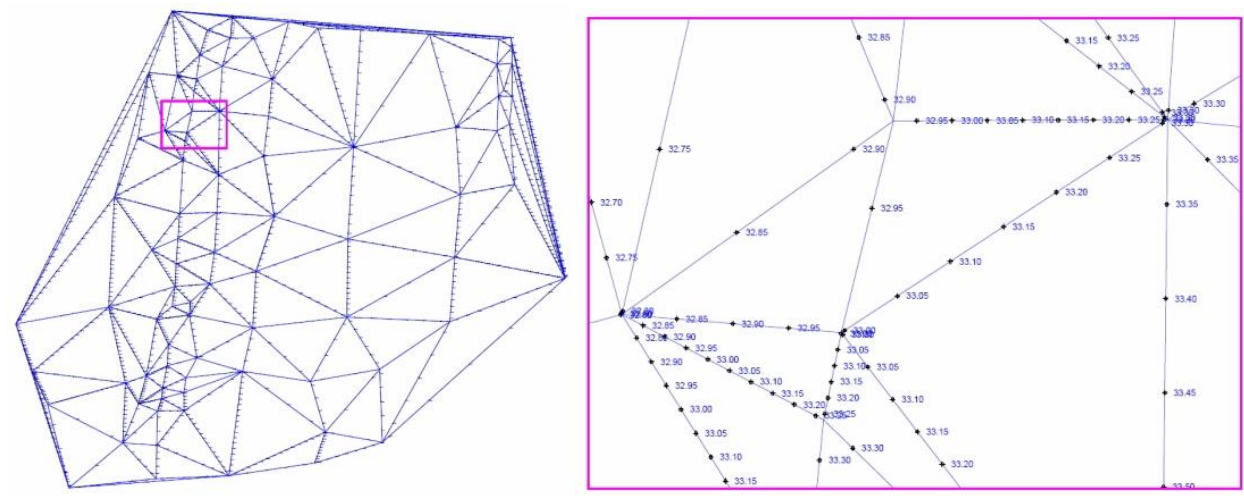

Fig. 6. The Delaunay triangulation among the selected topographic points using the program "Circle_3p".

Among these triangle vertices, horizontal interpolation was performed in the LAS07 height system using a selected step of $0.5 \mathrm{~m}$ (Fig. 7). The coordinates of 1676 extra points, plotted as horizontals, were calculated during the interpolation.

The interpolation points were uploaded to TopoPlan (AutoCAD 2016). The horizontals were plotted using the "Spline" function (Fig. 8).
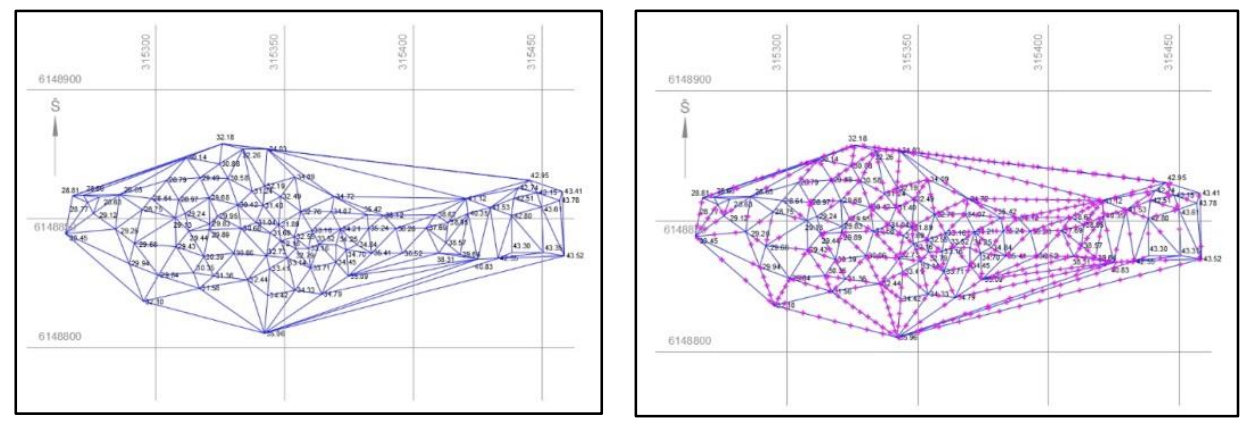

Fig. 7. The interpolation among the vertices of selected triangles in research area. 


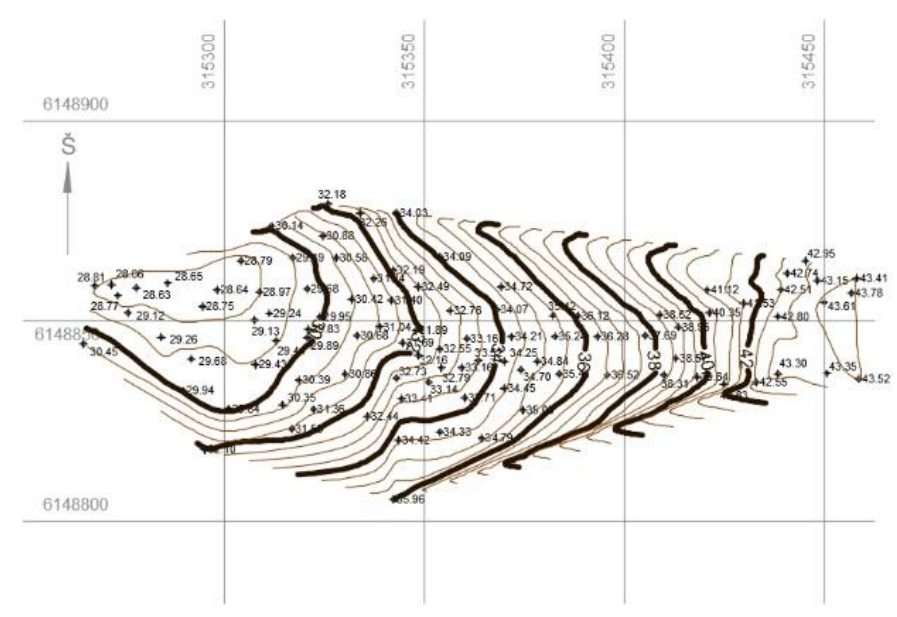

Fig. 8. The points of interpolation, an interpolation sequence and relief isolines in research area.

\section{Results}

In 2017 - 2019 surface fixation was carried out on the stretch of blowing dunes of the Curonian Spit (Juodkante - Pervalka). The study pursued two objectives. The first is to evaluate and compare the efficiency and accuracy of terrestrial geodetic measurements and aerometry of unstable dynamic surfaces; the second is to evaluate the influence of snow and vegetation on the accuracy of aerial photographs of unmanned aerial vehicles. Measurements were made in the Naglis Dune segment (aeolian salience), which is bounded deflation ravines on the south and north sides, and on the southern part of the Parnidis Dune, which descends into a wide inter-dune valley. Measurements (groundbased geodetic and UAV aero-images) was carried out in investigation area during the autumn and winter of 2017; spring, summer, fall, and winter of 2018 and spring of 2019 years.

Evaluation of precision of the aero-images. One of the most time-consuming tasks in aerial photography is to set out the ground control points (GCPs) and to coordinate them. Therefore, it is necessary to find out the optimal number of GCPs in order to minimize the preparatory work. It should also be possible to estimate the feasible use of co-ordinated stable land objects instead of bearing marks, which would further simplify the preparatory work. Therefore, 10 marks and 10 objects of land surface were formed in the measured area.

In order to evaluate the accuracy of the 3D model, it was created incorporating all ten marks and the coordinates of all the objects were measured in this model. The differences between the coordinates of objects in the 3D model and the coordinates measured during the topographic image practically do not exceed the double (Trimble GPS) accuracy in those objects. The accuracy of other objects is poorer due to the grass patches, which complicates their identification. 
The random error distribution depends on the accuracy of the object identification therefore the graph consists of taking the errors in absolute size in $\mathrm{mm}$.

The error analysis shows that they increase significantly when the orientation marks are fewer than 5, even for those objects that are visible in the 3D model. Therefore, it can be argued that in order to maintain the accuracy of measurements, there should be at least 5 orientation marks. It has been noticed that the error rate is influenced not only by the vegetation but also by the experience and thoroughness of the operator measuring the $3 \mathrm{D}$ model. As the precision of the well-known objects is practically unchanged (from 10 to 5 marks), it can be argued that the $3 \mathrm{D}$ model will be created with the maximum accuracy 5 GCPs and well-visible coordinated objects will be used (Table 1 and 2).

Table 1. The object errors when a $3 \mathrm{D}$ model is made on the basis of 10 marks.

\begin{tabular}{|c|c|r|r|}
\hline \multicolumn{4}{|c|}{ Absolute error size (mm) } \\
\hline Point No. & X & Y & Z \\
\hline np-28.81 & 54 & 77 & 74 \\
\hline $\mathrm{np}-29.26$ & 8 & 12 & 28 \\
\hline $\mathrm{np}-32.10$ & 15 & 14 & 24 \\
\hline $\mathrm{np}-30.86$ & 98 & 45 & 44 \\
\hline $\mathrm{np}-34.03$ & 32 & 43 & 69 \\
\hline $\mathrm{np}-35.42$ & 42 & 80 & 41 \\
\hline $\mathrm{np}-33.16$ & 14 & 13 & 32 \\
\hline $\mathrm{np}-36.28$ & 34 & 23 & 33 \\
\hline $\mathrm{np}-43.52$ & 5 & 11 & 24 \\
\hline $\mathrm{np}-41.53$ & 40 & 30 & 44 \\
\hline
\end{tabular}

Table 2. The comparison of absolute errors in different numbers of marks for precision calculation, mm.

\begin{tabular}{|c|c|c|c|c|c|c|c|c|c|c|c|c|}
\hline Point No. & \multicolumn{3}{|c|}{3 marks } & \multicolumn{3}{|c|}{4 marks } & \multicolumn{3}{c|}{5 marks } & \multicolumn{3}{|c|}{7 marks } \\
\hline & $\mathrm{x}$ & $\mathrm{y}$ & $\mathrm{z}$ & $\mathrm{x}$ & $\mathrm{y}$ & $\mathrm{z}$ & $\mathrm{x}$ & $\mathrm{y}$ & $\mathrm{z}$ & $\mathrm{x}$ & $\mathrm{y}$ & $\mathrm{z}$ \\
\hline $\mathrm{np}-28.81$ & 402 & 608 & 514 & 309 & 194 & 263 & 56 & 80 & 51 & 48 & 70 & 73 \\
\hline $\mathrm{np}-29.26$ & 86 & 105 & 56 & 36 & 42 & 42 & 11 & 12 & 26 & 10 & 9 & 19 \\
\hline $\mathrm{np}-32.10$ & 175 & 193 & 64 & 78 & 14 & 10 & 15 & 8 & 25 & 13 & 16 & 26 \\
\hline $\mathrm{np}-30.86$ & 95 & 145 & 574 & 48 & 33 & 254 & 95 & 56 & 57 & 88 & 39 & 49 \\
\hline $\mathrm{np}-34.03$ & 954 & 657 & 1419 & 692 & 170 & 164 & 48 & 46 & 52 & 37 & 38 & 55 \\
\hline $\mathrm{np}-35.42$ & 400 & 492 & 194 & 387 & 308 & 406 & 45 & 84 & 48 & 43 & 78 & 47 \\
\hline $\mathrm{np}-33.16$ & 102 & 266 & 88 & 56 & 32 & 39 & 16 & 11 & 28 & 11 & 15 & 29 \\
\hline $\mathrm{np}-36.28$ & 729 & 371 & 803 & 524 & 498 & 527 & 35 & 25 & 31 & 30 & 28 & 27 \\
\hline $\mathrm{np}-43.52$ & 109 & 145 & 188 & 64 & 75 & 84 & 17 & 14 & 26 & 9 & 16 & 22 \\
\hline $\mathrm{np}-41.53$ & 701 & 398 & 239 & 471 & 480 & 341 & 42 & 32 & 46 & 45 & 33 & 43 \\
\hline
\end{tabular}

A comparison of ground surveying and unmanned aerial photography was made in winter of 2018 year. season was made. Snow cover and its varying thickness have a significant impact on the accuracy of aerial imagery of UAF images photogrammetric 
interpretation. The UAV images fixed not the real surface of the dunes, but the snow cover, which has quite a different thickness. Comparison of the ground-based geodetic survey plan and the UAV aerial imagery shows that the largest mismatch in isoline position are at the foot of the meso-rang relief forms where are the largest snow accumulations (Fig. 12).

One of the possible the obstacle for correct position of isolines drawn from the UAV images was snow on the dune slopes (Fig 9 B). The problem is that the snow is giving reflection, and the photogrammetric software is not able to properly incorporate the key points in UAV images (in some places). As the result the maximal spatial mismatch of isolines seeks about 3 meters $(2.88 \mathrm{~m})$ and average mean squared deviation is about $\pm 1,25$ (maximal $\pm-2.05 \mathrm{~m}$ )(Fig. 10 and 11, Table 3 ). The measurements are strongly influenced by the snow on the surface of the dunes.

More over there is no stable objects which could be used as GCP's in dunes. As the result it could cause the isolines mismatches results (Fig. 11). The results of previous research showed that $5 \mathrm{GCP}^{\prime} \mathrm{s}$ is a strong argument for the better precision and the surface covered by grass.

Table 3. Comparison of the relief isolines position (UAV's and precision ground measurements data)

\begin{tabular}{|c|c|c|c|c|c|c|c|c|c|}
\hline \multicolumn{10}{|c|}{ Slope with a thick snow cover (Winter 2018) } \\
\hline $\begin{array}{l}\text { Mismatches } \\
\text { of isolines } \\
\text { position, } m\end{array}$ & $\begin{array}{l}\text { Mean } \\
\text { squared } \\
\text { deviation, } \\
|\Delta|\end{array}$ & $\begin{array}{l}\text { Mismatches } \\
\text { of isolines } \\
\text { position, } \mathrm{m}\end{array}$ & $\begin{array}{l}\text { Mean } \\
\text { squared } \\
\text { deviation, } \\
|\Delta| \\
\end{array}$ & $\begin{array}{l}\text { Mismatches } \\
\text { of isolines } \\
\text { position, } m\end{array}$ & $\begin{array}{l}\text { Mean } \\
\text { squared } \\
\text { deviation, } \\
|\Delta|\end{array}$ & $\begin{array}{l}\text { Mismatches } \\
\text { of isolines } \\
\text { position, } m\end{array}$ & $\begin{array}{l}\text { Mean } \\
\text { squared } \\
\text { deviation, } \\
|\Delta|\end{array}$ & $\begin{array}{l}\text { Mismatches } \\
\text { of isolines } \\
\text { position, } \mathrm{m}\end{array}$ & $\begin{array}{l}\text { Mean } \\
\text { squared } \\
\text { deviation, } \\
|\Delta|\end{array}$ \\
\hline $\mathrm{A}-\mathrm{A}$ & & B-B & & $\mathrm{C}-\mathrm{C}$ & & $\mathrm{D}-\mathrm{D}$ & & & \\
\hline & 0.227 & 2.88 & 2.052 & 2.05 & 1.483 & 0.00 & 0.31 & 0.00 & 0.61 \\
\hline 1.16 & 0.632 & 0.93 & 0.102 & 0.61 & 0.043 & 0.36 & 0.05 & 0.37 & 0.24 \\
\hline 1.04 & 0.513 & 1.32 & 0.492 & 1.30 & 0.733 & 0.50 & 0.19 & 0.98 & 0.37 \\
\hline 0.58 & 0.053 & 1.19 & 0.362 & 0.39 & 0.177 & 0.15 & 0.16 & 0.71 & 0.10 \\
\hline 0.20 & 0.327 & 0.03 & & & 0.567 & 0.51 & 0.20 & 0.35 & 0.26 \\
\hline 0.53 & 0.003 & 0.24 & 0.588 & 0.89 & 0.323 & 0.17 & 0.14 & 1.02 & 0.41 \\
\hline 0.55 & 0,023 & 0.50 & 0.328 & 0.29 & 0.277 & 0.49 & 0.18 & 0.84 & 0.23 \\
\hline 0.59 & 0.063 & 0.36 & 0.468 & 0.23 & 0.337 & 0.14 & & & \\
\hline$\frac{0.63}{0.64}$ & 0.103 & 0.00 & 0.828 & 0.43 & $\frac{0.137}{0.217}$ & 0.47 & 0.16 & & \\
\hline $\begin{array}{l}0.04 \\
0.11\end{array}$ & $\frac{0.113}{0.110}$ & & & $\begin{array}{l}0.35 \\
0.17\end{array}$ & $\frac{0.217}{0.397}$ & & & & \\
\hline & & & & 0.10 & 0.467 & & & & \\
\hline Total & 0653 & & 1899 & & 1488 & & 0.493 & & 0.830 \\
\hline
\end{tabular}

A

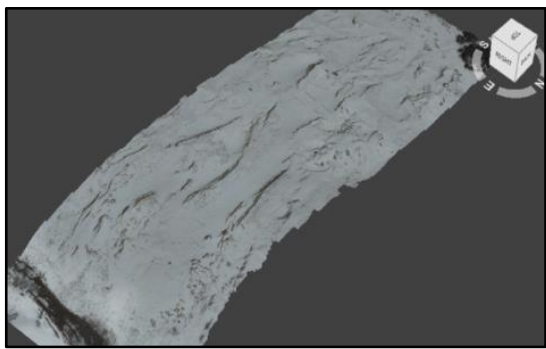

B

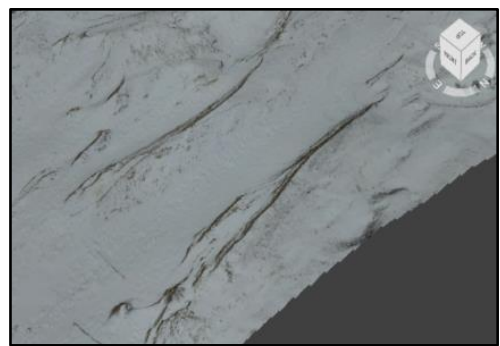

Fig. 9. Fragments of blowin dunes: A - without snow cover, B - with snow cover. 


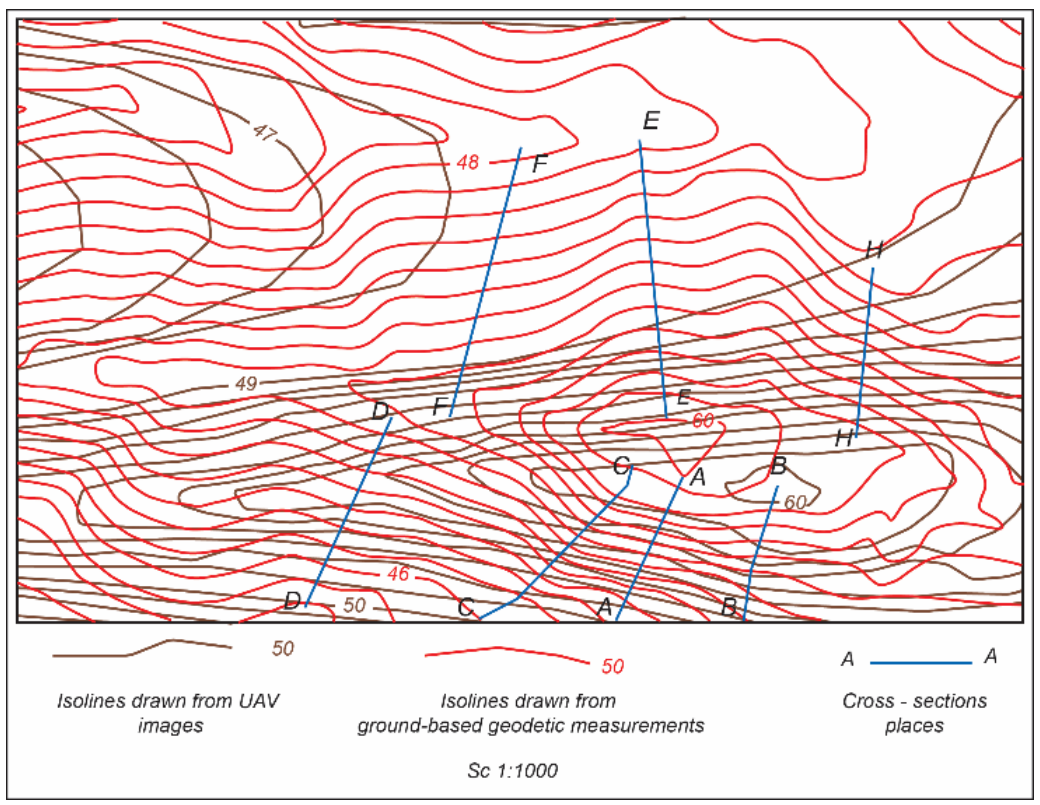

Fig. 10 Comparison of mismatches of relief isolines position drawn from UAV images and from ground-based measurements data in winter time.

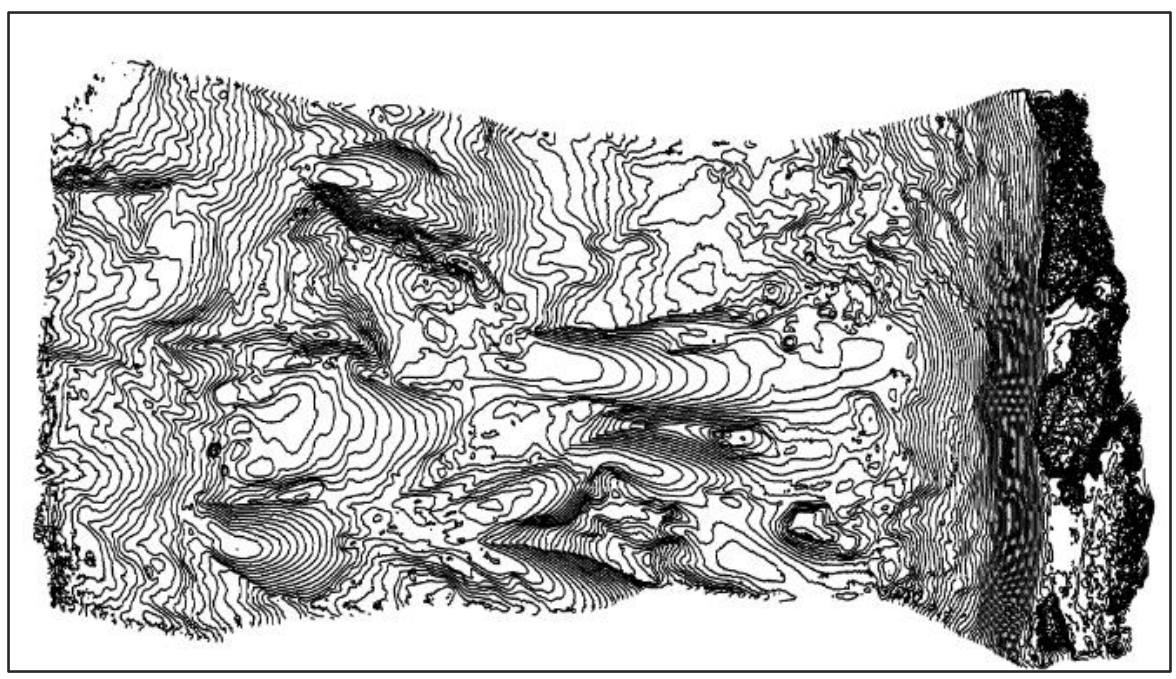

Fig 11. The shape of isolines drawn by photogrammetric software „Pixprocessing“. 


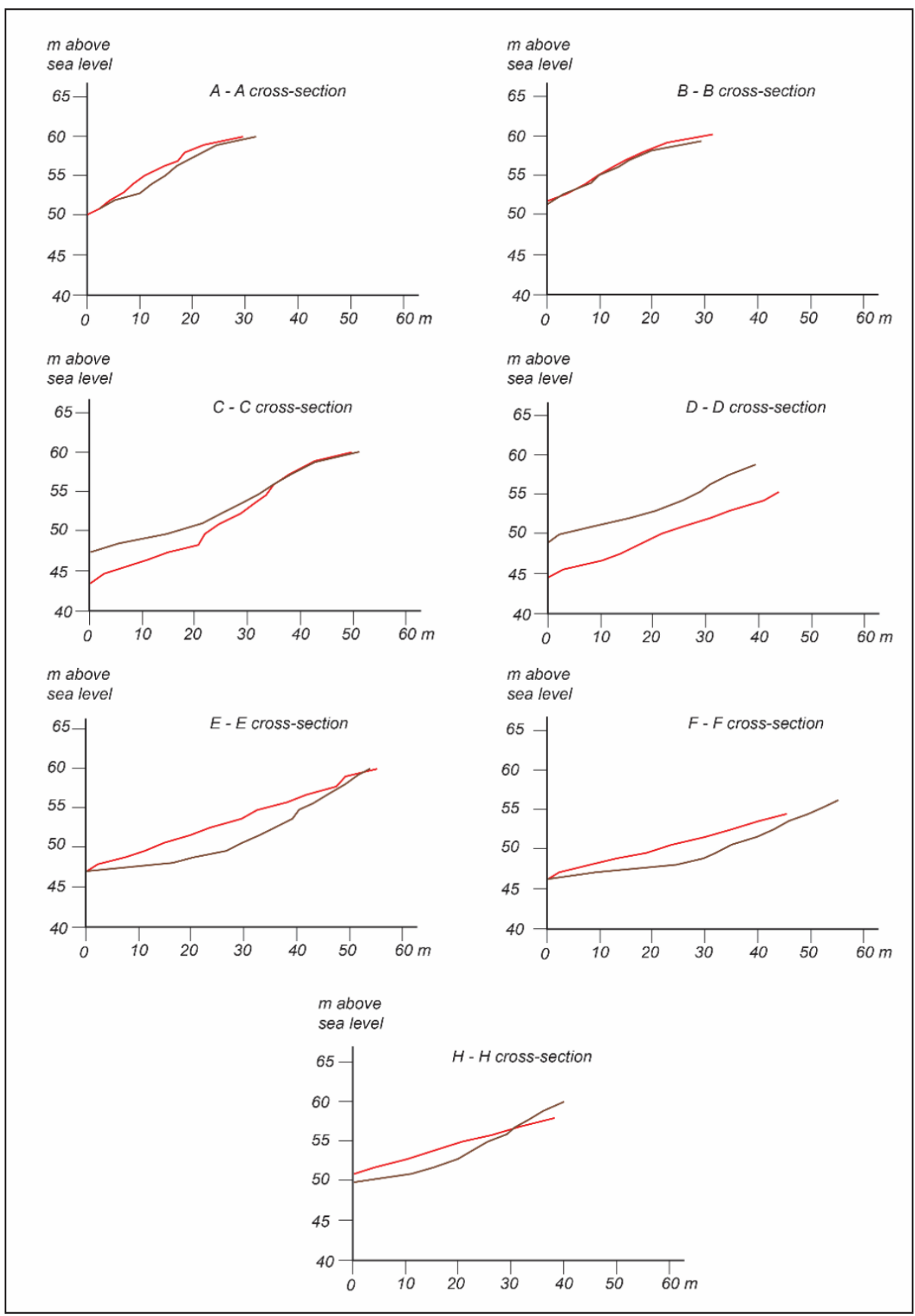

Fig. 12. Comparison of mismatch of relief cross-section drawn from UAV images and from ground-based geodetic measurements data in winter time.

Places of cross-section are shown in Fig. 10. 


\section{Conclusions}

1. Evaluation of accuracy of the created ortophotographic model shows that difference between the co-ordinates of control points on the surface of the sand dune measured by Trimble GPS and co-ordinates estimated from the ortophotographic model differ not more than $\pm 4-6 \mathrm{~cm}$. That allows asserting that in the future the number of measured markers necessary for a topographic map can be reduced 2-3 times.

2. The comparison of the results of the geodetic measurements and the UAV images, showed that the best overlaps of surface microform isolines are in steep slopes. On the flat surface microform variance makes up 0.7-1.0 meters. This is due to the rare density of the interpolation points calculated by the program "Circle $3 p$ ". The variance of the isolines at the foot of the dune reaches $0.45-0.7 \mathrm{~m}$ and $0.95-1.35 \mathrm{~m}$ (in high grass patches). The study has shown that external factors have a significant influence on the identification of the surface microforms.

3. The research related to the GCPs position shows that 5 GCPs arranged at the edges and the centre of the object give the best accuracy compared to other variations. The best results of aerial photographs are obtained even when the shortest distance between GCPs points does not exceed $20 \mathrm{~m}$.

4. The efficiency of automated points height interpolation of ground-based measurements is improved by the computer program "Circle_3p" created by in Department of Cartography and Geoinformatics Vilnius University (author: Dr. Artūras Bautrènas). The operation of the program is based on the classical Delaunay method and ensures a consistent systemic selection of points. The use of "Circle $3 p$ " for the analysis of aerial photographs of the Curonian Spit dunes has shown that the program needs to be improved by adding the elements for correction of the isolines.

5. The snow is giving reflection, and the photogrammetric software is not able to properly identify the key points in UAV images (in some places). As the result the average mean squared deviation is about 1,25 .

\section{References}

Adams, M. L., Philpot, W. D., Norwell W.A. (1999). Yellowness index: an application of spectral second derivatives to estimate chlorosis of leaves in stressed vegetation application of spectral second derivatives to estimate chlorosis of leaves in stressed vegetation, International Journal of Remote Sensing, 20(18), 3663-3675.

Baluja, J., Diago, M.P., Balda, P., Zorer, R., Meggio, F., Morales, F., Tardaguila, J. (2012). Assessment of vineyard water status variability by thermal and multispectral imagery using an unmanned aerial vehicle (UAV), Irrigation Science, 30(6), 511-522.

Bellvert, J., Zarco-Tejada, P.J., Girona, J., Fereres, E. (2013). Mapping crop water stress index in a Pinot-Noir vineyard: Comparing ground measurements with thermal remote sensing imagery from an unmanned aerial vehicle, Precision Agriculture, 15(4), 361-376.

Benassi, F., Dall'Asta, E., Diotri, F., Forlani, G., Cella, U.M., Roncella, R., Santise, M. (2017). Testing accuracy and repeatability of UAV blocks oriented with GNSS-supported aerial triangulation. Remote Sensing. Vol. 9. Issue 2., 172. 
Berni, J., Zarco-Tejada, P.J., Suarez, L., Fereres, E. (2009). Thermal and narrowband multispectral remote sensing for vegetation monitoring from an unmanned aerial vehicle, IEEE Transactions on Geosciences and Remote Sensing, 47(3), 722-738.

Chisholm, R.A., Cui, J., Lum, S.K.Y., Chen, B.M. (2013). UAV LiDAR for below-canopy forest surveys, Journal of Unmanned Vehicle System, 1, 61-68.

Fang, T., Piegl, L. (1992). Algorithm for Delaunay triangulation and convex hull computation using a sparse matrix, Computer Aided Design, 24, 425-436.

Forlani, G., Dall'Asta, E., Diotri, F., Cella, U.M. di Roncella, R., Santise, M. (2018). Quality assessment of DSMs produced from UAV flights georeferenced with on-board RTK positioning, Remote Sensing, 10, 311 .

Huesca, M., Merino-de-Miguel, S., González-Alonso, F., Martinez, S., Miguel Cuevas, J., Calle, A. (2013). Using AHS hyper-spectral images to study forest vegetation recovery after a fire, International Journal of Remote Sensing, 34(11), 4025-4048.

Hugenholtz, C., Brown, O., Walker, J., Barchyn, T., Nesbit, P., Kucharczyk, M., Myshak, S. (2016). Spatial accuracy of UAV-derived ortho-imagery and topography: Comparing photogrammetric models processed with direct geo-referencing and ground control points Geomatica, 70, 21-30.

Hugenholtz, C.H., Whitehead, K., Brown, O.W., Barchyn, T.E., Moorman, B.J., LeClair, A.J., Riddell, K., Hamilton, T. (2013). Geomorphological mapping with a small unmanned aircraft System (SUAS): Feature detection and accuracy assessment of a photogrammetrically-derived digital terrain model, Geomorphology, 194. 16-24.

Kaneko, K., Nohara, S. (2014). Review of effective vegetation mapping using the UAV (Unmanned aerial vehicle) method, Journal of Geographic Information System, 6, 733-742.

Knoth, C., Klein, B., Prinz, T., Kleinebecker, T. (2013). Unmanned aerial vehicles as innovative remote sensing platforms for high-resolution infrared imagery to support restoration monitoring in cut-over bogs, Applied Vegetation Science, 16(3), 509-517.

Laliberte, A.S. and Rango, A. (2009). Texture and scale in object-based analysis of subdecimeter resolution unmanned aerial vehicle (UAV) imagery, IEEE Transactions Geoscience and Remote Sensing, Vol. 47. 761-770.

Malthus, T.J., Madeira, A.C. (1993). High resolution spectro-radiometry: Spectral reflectance of field bean leaves infected by Botrutis Fabae, Remote Sensing of Environmental, 45(1), 107116.

Ruzgienė, B., Berteška T., Gečytė S., Jakubauskienė E., Aksamitauskas, V.Č. (2015). The surface modelling based on UAV photogrammetry and qualitative estimation, Measurement, 73, 619-627.

Salami, E., Barrado, C., Pastor, E. (2014). UAV flight experiments applied to the remote sensing of vegetation area, Remote Sensing, 6, 11051-11081.

Shahbazi, M., Sohn, G., Théau, J., Menard, P. (2015). Development and evaluation of a UAVphotogrammetry system for precise 3D environmental modelling, Sensors, 15, 2749327524.

Turner, D., Lucieer, A., Watson, C. (2012). An automated technique for generating georectified mosaics from ultra-high resolution unmanned aerial vehicle (UAV) imagery, based on structure from motion (SFM) point clouds, Remote Sensing, 4, 1392-1410.

Sužiedelytė-Visockienė, J., Bručas, D., Bagdžiūnaitè, R., Puzienė, R., Stanionis, A., Ragauskas, U. (2016). Remotely-piloted aerial system for photogrammetry: orthoimage generation for mapping applications, Geografie, 121, 349-367.

Whitehead, K, Hugenholtz, C.H. (2014). Remote sensing of the environment with small unmanned aircraft systems (UASs). Part 1: A review of progress and challenges, Journal of Unmanned Vehicle Systems, 2(3), 69-85

Whitehead, K, Hugenholtz, C.H., Myshak, S., Brown O.W., LeClai,r A.J., Tamminga, A., Barchyn, T.E., Moorman, B.J., Eaton, B. (2014). Remote sensing of the environment with small unmanned aircraft systems (UASs). Part 2: Scientific and commercial applications, Journal of Unmanned Vehicle Systems, 2(3), 86-102. 
Zarco-Tejada, P.J., Miller, J.R., Noland, T.L., Mohammed, G.H., Sampson, P.H. (2001). Scalingup and model inversion methods with narrowband optical indices for chlorophyll content estimation in closed forest canopies with hyperspectral data, IEEE Transactions on Geosciences and Remote Sensing, 39(7), 1491-1507.

Zhang, L., Sun, X., Wu, T., Zhang, H. (2001). An analysis of shadow effects on spectral vegetation indexes using a ground-based imaging spectrometer, Geoscience and Remote Sensing Letters, 12(11), 2188-2192.

Received December 22, 2019, accepted December 27, 2019

\section{Authors' information}

Algimantas Česnulevičius - Dr. Habil., Professor. Head of the Department of Cartography and Geoinformatics.

Author and co-author of 5 monographs, 6 textbooks and 180 articles.

Member of the editorial board of scientific journals:

Geology. Geography (Lithuanian Academy of Sciences),

Geodesy and Cartography (Vilnius Gediminas Technical University),

Polish Cartographical Review (Polish Geographical Society),

Baltica (Lithuanian Academy of Sciences).

Scientific interests: geomorphologic processes, thematic mapping, history of cartography, UAV and remote sensing.

Artūras Bautrėnas - Dr., Associated professor.

Author and co-author of 2 text-books, about 50 scientific articles.

Scientific interests: geomorphologic processes, thematic mapping, UAV and remote sensing.

Linas Bevainis - Dr., Assistant.

Co-author of 1 text-book and about 20 scientific articles.

Scientific interest: UAV and remote sensing.

Neringa Mačiulevičiūtè - Turlienè - Ph.D student.

Co-author of 5 scientific articles.

Scientific interest: geomorphologic processes, thematic mapping. 